\title{
BESKIK DIE KERKORDE OOR SELFSTANDIGE GESAG? IS DIE KERKORDE 'N WET?
}

Ds. C. J. Smit

Vir die Skriftuurlike gebruik van die kerkorde in die kerklike lewe is duidelikheid oor die vrae wat in die titel verwoord is, van deurslaggewende belang. ' $n$ Mens se antwoorde op die vrae sal bepaal of jy van die kerkorde 'n selfstandige gesagsinstelling naas die Woord van God gaan maak, en dit derhalwe as 'n jurisdiens-dwingende wet gaan toepas en of 'n mens in jou hantering van die kerkorde laasgenoemde as ' $n$ bediening van die Skrifgesag gaan beskou en derhalwe Jesus Christus de facto as die Alleenregeerder van sy kerk gaan erken. Hoe moet oor die gesag van die kerkorde geoordeel word?

\section{Verskillende beskouinge}

Vir Van den Berg (1969:56) is die kerkorde nie slegs 'n bundel menslike insettinge waardeur die kerk "ingekerker" word nie, maar ook 'n historiese ergernis waaraan hoegenaamd geen gesag toegeken behoort te word nie.

Brunner (1939:318) plaas die kerk as sigbare instituut onder die 'natuurlike gemeenskappe'. Die konsekwensie van hierdie standpunt is dat die kerkorde, volgens die reëls van alle natuurlike gemeenskappe, 'n reglement is met bloot kontraktuele gesag vir die ordening van die kerklike lewe en die saamdoen van kerke aan dié ordening. Die regspositiwistiese standpunt, naamlik dat 'n besluit geldig en afdwingbaar is bloot omdat die kerkraad of sinode besluit het, beheers hierdie kerkregtelike beskouing.

Van Staden $(1973: 15,16)$ ken aan die kerkorde selfstandige gesag toe. Hy motiveer hierdie gesag soos volg: dit rus i) op die Woord van God; ii) op die belydenis; iii) op die feit dat Christus self die regeeramp ingestel het, waaraan $\mathrm{Hy}$ die bevoegdheid gegee het om riglyne vir die goeie orde van die kerklike lewe vanuit die Skrifbeginsels vas te stel; en iv) op die Bybelse eis van onderwerping en gehoorsaamheid aan die kerklike mag of regeeramp. Die geldigheid ( of ongeldigheid) van die kerkorde word vir hom op 'n juridiese wyse deur die bevoegde kerklike vergadering bepaal.

Nauta (1971:19) sien 'gesag van die kerkorde' in die nouste samehang met die verhouding 'kerkorde: Heilige Skrif' en 'kerkorde: belydenis'. Hiervolgens gaan die gesag van die kerkorde direk van Christus uit waar die kerkordebepalinge direk op die Woord en op die belydenis gefundeer is. In die geval van regulatiewe bepalings rus die kerkorde op 'kerklike gesag'. Die bepalings met direkte binding aan die Heilige Skrif of die belydenis dra 'n ander gesagskarakter as dié bepalings wat slegs op 'kerklike ooreenkoms' rus.

Nauta se beskouing van 'kerklike gesag' kom ooreen met die van Jansen, hoewel Jansen (1923:2) daaraan ook 'ampsgesag' toevoeg: hy stel die gesag van die kerkorde op die gebod van onderwerping aan die 'ampsdraers', soos wat die kinders gehoorsaamheid aan die ouers verskuldig is (Ef. $6: 1-3$ en Kol. $3: 20$ ) en soos wat die onder- 
dane aan die owerheid verskuldig is ( $\mathrm{Rm} .13: 1-7)$. So eis die Here ook gehoorsaamheid aan "'de Kerkelijke machten", blykens Matteus $16: 19 ; 18: 18$; Johannes $20: 21,23$; Handelinge $15: 27-29$ en veral Hebreërs 13:7 en 17: "Wees gehoorsaam aan julle voorgangers en onderdanig, want hulle wak vir julle siele as diegene wat rekenskap moet gee, sodat hulle dit met blydskap kan doen en nie al sugtende nie; want dit is vir julle nie nuttig nie". Maar die Here alleen kan die gewetens bind (Jk. $4: 12$ ), daarom sê Jansen $(1923: 2)$ ten opsigte van die 'ampsdraers': "Haar gezag draagt echter geen consciëntiebindend, maar wel een kerkelijk karakter'. Die kerklike bepalinge dra 'n reëlende karakter en bind die gewetens slegs in soverre dit aan die Skrif ontleen is.

\section{Die gesag setel in die Woord}

Teenoor genoemde standpunte moet die geestelike en die bedienende karakter van die kerkorde benadruk word in teenstelling met die reglementêre en juridies-dwingende. Christus eis deur die kerkorde gehoorsaamheid van sy kerk, 'n gehoorsaamheid wat Hyself kragtens die genadeverbond ook aan sy kerk skenk. Die kerk kan nie as kerk bestaan as Christus nie as Hoof daarvan erken word en die regering daarvan nie ooreenkomstig sy Woord ingerig is nie. Hoewel Christus van mense gebruik maak in die regering van sy kerk, dra Hy nie sy gesag aan hulle oor nie. Deur hulle oefen hy sý gesag uit: "Wat Christus beveelt, heeft absoluut gezag, maar de opzieners der gemeente hebben uit zichzelven niets te zeggen, maar alleen als bedienaars des Woords" (Bouwman, 1970:2). Die klem moenie geplaas word op die bedienaars as 'ampsbekleeërs' nie - die gesag setel nie in die 'amp' nie. Die klem moet geplaas word op bedienaars des Wóórds - die gesag setel in die Woord. Volgens Matteus 16:19 setel die 'afgeleide' of 'gedelegeerde' gesag - uit die aangetoonde beskouings van Nauta en Jansen - nie in die 'struktuur' of in die 'amp' nie, maar in die dienaar-se-hantering-van-die-sleutels-van-die koninkryk.

Dat die gesag nie in 'n orgaan of 'n struktuur setel nie, blyk daaruit dat dit onmiddellik deur God die Heilige Gees met en deur die Woord in die gelowige uitgeoefen word, sowel as middellik deur sy organe wat sy Woord bedien: in alle gevalle bly dit God se gesag wat in die kerk bedien word. (Spoelstra, 1978:10). Christus se gesag is die enigste in die handhawing van kerklike ordebepalings: "Om vas te stel of ' $n$ handeling in die kerk toelaatbaar is, moet oorweeg word of dit die oppergesag van Christus erken of in gedrang bring. Wanneer die gesag van Christus in gedrang kom, dan word selfs ' $n$ formele handeling ontoelaatbaar" (Van der Walt, 1976: 37).

Die vraag na kerkordelike gesag was vir die leiersfigure in en direk na die reformasie 'n vraag na Skrifgesag. Vir Bucer het dit byvoorbeeld nie ingehou dat die kerkorde gelyk aan die Skrif gestel moes word nie, maar wel dat die kerkorde vir hom geen gesag sou hê as daardeur nie die Skrifbeginsels bedien sou word nie: hetsy in soveel woorde uitgedruk, hetsy deur middel van 'n evidente en ontwyfelbare sillogisme daaruit afgelei (Van't Spijker, $1972: 27,28$ ). 
Vir Calvyn (1956 : IV, II, 4; IV, III, 1, 2, 7, 8, 14; IV, VIII, 23; IV; VIII( 1-4, 7-8) gaan dit in die kerkregering geheel en al om Christus wat met sy eie gesag deur sy Woord en Gees regeer. Daarvoor gebruik Hy die herders en opsieners, of ouderlinge. Die kerk is daar waar die orde van Woordbediening, sakramentsbediening en tug gehandhaaf word. Hy handhaaf die drieërlei vorme van kerklike gesag: potestas regiminis (om te reël), potestas docenda (om te leer) en potestas gubernatio (om te regeer). Die gesag moet met die oog op die opbou van die kerk uitgeoefen word en bly aan die Woord van die Here gebonde. As sodanig is die 'kerklike gesag' vir Calvyn nie 'n selfstandige gesag op sigself nie, maar dit is aan die Woord onderworpe en daardeur begrens. Hy kan slegs bepalings aanvaar wat op Gods gesag gefundeer en aan die Skrif ontleen is. Alles wat hieraan nie beantwoord nie is vir hom geheel en al menslike oorlewering.

In die geskiedenis van die Gereformeerde teologie is met betrekking tot die Skrifgesag van vroeg af onderskei tussen normatiewe en historiese gesag (Heyns, 1977:162. Hoewel hy van skopiese en periferiese gesag praat, gee ek voorkeur aan die geykte Gereformeerde terme in die verband). Op dieselfde wyse kan onderskei word met betrekking tot die kerkorde se bediening van die Skrifgesag. Die kerkorde bedien die Skrifgesag vir die kerklike lewe enersyds op 'n normatiewe wyse deur middel van die kerkregtelike bepalings wat direk of indirek uit die Skrif af te lei is (vgl. Nederlandse Geloofsbelydenis, artikel 30). In hierdie opsig is die kerkorde gewetensbindend, en wel omdat die Skrif gewetensbindend is (byvoorbeeld die feit dat ouderlinge verkies moet word: Kerkorde, artikel 22). Andersyds bedien die kerkorde die Skrifgesag vir die kerklike lewe op 'n historiese wyse deur middel van praktiese, organisatoriese reëlings wat bepaal word deur plek- (waaronder kulturele-) en tydsomstandighede waartoe die kerk die Skriftuurlike bevoegdheid het, volgens 1 Korintiërs $14: 40$ en Die Nederlandse Geloofsbelydenis, artikel 32 . Hierdie bepalings moet tot die absolute noodsaaklike beperk word en dit mag nie met die algemene strekking en gees van die Skrif bots nie (Calvyn $1956: \mathrm{IV}, \mathrm{X}, 30$ ). In hierdie opsig is die kerkorde nie gewetensbindend nie (byvoorbeeld, die wyse waarop ouderlinge verkies moet word: Kerkorde, artikel 22).

\section{Kerkorde is bediening van Skrifgesag}

Ek konkludeer dat die kerkorde nie gesag in homself, naas die Skrif, het nie: die kerkorde bedien slegs die Skrif se gesag, aan die hand van die belydenis. Soos wat in die Gereformeerde dogmatiek die gesag van die Heilige Skrif geformuleer is as norma normans (normerende norm) en die gesag van die belydenis as norma normata (genormeerde norm) (vgl. Heyns, 1977:161), só kan die kerkorde hier gestel word as norma ministrans (bedienende norm, oftewel bediening van die norm). Hier vind dus geen gesagsoordrag plaas nie. Die gesag van die Heilige Skrif word nie die gesag van die kerkorde nie. Die kerkorde en die Heilige Skrif kom dus nie naas mekaar te staan nie. In die Skrif spreek God deur middel 
van mense wat $\mathrm{Hy}$ as Bybelskrywers gebruik het! in die kerkorde spreek mense in gehoorsaamheid aan die Skrif deur die werkinge van die Heilige Gees. Die kerkorde bly derhalwe in die eerste plek mensewoord en daarom sowel kwalitatief as kwantitatief nie identies met Gods Woord nie.

\section{Kerkorde en wet}

Uit die voorafgaande beredenering is dit reeds duidelik dat daar met die kerkorde nie op dieselfde wyse as met 'n staatswet omgegaan kan word nie, omdat die kerklike regsuitoefening wesenlik van die wêreldlike regsuitoefening te onderskei is. Die kerkorde eis vrye gehoorsaamheid uit liefde; die wet dwing nakoming deur strafmaatreëls af. Die kerkorde wys van homself af weg: deur die kerkorde word gehoorsaamheid aan die Heilige Skrif gereël. Die wet wys na homself: deur die wet word gehoorsaamheid aan die wet as sodanig afgedwing. Die toepassing van die kerkorde word bepaal deur geloof, bekering, berou, sowel as omstandighede en motiewe; die toepassing van die wet vra nie bekering nie en hou nie rekening met berou nie, maar eis vergelding vir die harmonisering van belange (vgl. Roeleveld, $1972: 45$ ).

Derhalwe is die kerkorde nie 'n wetboek met tallose artikels op welke oortreding allerlei strafmaatreëls in werking gestel word nie, maar ' $n$ ordereëling ter toepassing van die beginsels van die kerkreg wat in Gods Woord direk gegee is en indirek af te lei is met die allesbeheersende uitgangspunt dat Christus die Hoof van sy kerk is en dat alleen sý bevele gewetensbindend is (Hovius, $1962: 14$ ). Dit beteken dat dit in die kerklike regsuitoefening nooit om oortredinge van die kerkorde gaan nie - soos wat dit in die wêreldlike regsuitoefening wel om oortredinge van die staatswette gaan. Die kerkorde is die beginseldraende modus quo waardeur die kerk op Skrifgronde opgebou word.

'n Oortreding van die kerkorde is dus slegs 'n oortreding in soverre dit 'n oortreding van die Heilige Skrif is, terwyl 'n oortreding van 'n wet op sigself 'n oortreding is.

Die begrip 'wet' is veral sedert die agtiende eeu deur die rasionalistiese regspositiwisme vereng om gehoorsaamheid bloot op formele gronde te eis (Van der Linde, 1980/81:37). As sodanig het die wet gebiedende en bindende krag - bloot omdat dit daar is, omdat dit afgekondig is deur 'n formele, deur die mens erkende regsvormende liggaam. Hieruit blyk ook dat die staatswet die burgery regspositiwisties aan homself bind, terwyl die kerkorde die kerk nie aan homself nie, maar aan die Skrif bind.

Die geformuleerde orde vir die kerk is dus by voorkeur geen wet nie, dit funksioneer anders en dit word anders toegepas. Die toepassing van' die kerkorde is ordening, wél in 'n bindende betekenis, omdat dié ordening op grond van die Skrif plaasvind, waarin Christus sy wet aan sy kerk gegee het (Van der Linde, 1965:108, 109; A. Kuyper, $1998: 13-15)$.

Van Dellen en Monsma (1941:13) se mening dat die kerkorde nie 'n wet is nie, is korrek, maar hulle motivering verskraal die kerkorde bloot tot sy regulatiewe faset: "The Church Order is 
moral in character, not judicial. It is a regulatory set of rules, not a legalistic set of laws".

Barth (1958:682) praat van 'kerkwet', maar bedoel daarmee geensins 'wet' nie - soos dit afgelei kan word in die onderskeid wat hy tussen 'kerkwet' en alle ander vorms van 'wette' maak. Die kerkgemeenskap is nie ' $n$ wet in homself nie en in sy verhouding met Christus is Hý die lewende wet van die kerk: "In great things and small, in all things, true Church law arises from a hearing of the voice of Jesus Christ. Neither formally nor materially does it arise elsewhere ... But we must be more precise and say that the voice which has to be heard is that of Jesus Christ as attested in Holy Scripture". Hiermee het Barth in die opsig by Calvyn (1956 : IV, X, 6.) aangesluit, waar laasgenoemde sê dat wette wat uit die mens self - sonder die Woord - voorgeskryf word, geen plek in die kerk mag hê nie.

Calvyn (1956:IV, X) praat deurgaans van 'wette' in sy verwysing na 'kerklike ordinansies. 'n Ondersoek na hierdie woordgebruik in die Institusie laat egter duidelik blyk dat Calvyn nie van 'wet' in 'n staatsregtelike betekenis van die woord praat nie, en dat die uitgangspunt vir sy wetsbeskouing ook nie die kerk is nie, maar die Skrif. Wesenlik bedoel Calvyn die Skrifbeginsels met betrekking tot die kerkregering waar hy van 'wette' ten opsigte van die kerk praat. Derhalwe kan aanvaar word dat Calvyn van 'kerkorde' praat as hy dit oor 'kerkwette' het.

Trouens die benaming "kerkenordening" is ná Calvyn, vir die eerste keer in 1581 by die sinode van Middelburg, gebruik. Die voorafgaande sinodes (Wezelkonvent, 1568; Emden, 1571; Dordrecht, 1574,1578 ) het soos dit tydens die reformasie die gebruik was van "acta" of "artikels" van die sinode gespreek (Rutgers, 1980:38, 39). Kerkorde en wet is histories nooit met mekaar gelykgestel nie. Wat die sinodes van die begin van die reformasie af vasgestel het, was nie 'n wet of 'n statuut nie, maar kennelik 'n kerkorde: nie as 'n las en 'n reglement nie, maar as 'n middel "om goede ordre inder Ghemeente Christi te onderhouden." Dit het meegebring dat die kerkorde van die tyd van die reformasie of anders as 'n wet toegepas is, daar was steeds ruimheid, omdat die kerkorde die kerke nie aan homself gebind het nie. Formalisme of reglementêre presiesheid was vreemd aan die bedoeling van die kerkorde (Rutgers, $1890: 39,41$ ).

\section{Konklusie}

Samevattend kan gestel word dat dit in die presbiteriale kerkregegering nooit die bedoeling was om die kerkorde as 'n 'kerkwet' of 'n 'sinodewet' te hanteer en daarvoor as 'n selfstandige grootheid te buig nie. Die kerkorde mag nie om sy eie ontwil afgedwing word nie. Die kerkorde is ook nie 'n juridiese instrument nie: "Kirchliche Ordnung ist geistliche Ordnung" (Geiger, 1954:31). Die kerkorde is niks minder nie, maar ook niks meer nie as bediening van die Skrifgesag (Van der Linde, 1977/78:3, 4; Van der Walt, $1976: 37$; Spoelstra, $1978: 10)$.

Om dié rede mag daar nooit eiewilligheid of willekeur ten op- 
sigte van die handhawing van die kerkorde toegelaat word nie.

Terugskouing:

Die kerkorde het nie bloot kontraktuele gesag, of selfstandige, juridies-dwingende gesag nie. Die kerkorde rus ook nie op 'n selfstandige 'kerklike gesag' nie. Trouens die kerkorde het geen gesag in homself, naas die Heilige Skrif nie. Christus oefen sy gesag deur mense uit, sonder om sy gesag aan hulle oor te dra of dit aan 'n 'struktuur' te delegeer. Die kerkorde is norma ministrans, 'n bedienaar van die Skrifgesag: op 'n normatiewe sowel as 'n historiese wyse.

Derhalwe is kerklike regsuitoefening wesenlik van die wêreldlike regsuitoefening te onderskei. Die kerkorde wys weg van homself af: deur die kerkorde word gehoorsaamheid aan die Skrif gereël; die wet wys na homself: deur die wet word gehoorsaamheid aan die wet as sodanig afgedwing. In die kerklike regsuitoefening gaan dit nie om oortredinge van die kerkorde nie- soos dit in die wêreldlike regsuitoefening wel om oortredinge van die staatswette gaan. 'n Oortreding van die kerkorde is slegs 'n oortreding in soverre dit 'n oortreding van die Heilige Skrif is. Die kerkorde se funksie is ordening op grond van die wet wat Christus in die Skrif aan sy kerk gegee het.

\section{LITERATUUR}

Barth, K. 1958. Church dogmatics, boek IV. dl. 2. (Uit Duits vertaal deur G. W. Bromiley). Edinburgh: Clark.

Bouwman, H. 1970. Gereformeerd kerkrecht. dl. 1. Kampen: Kok.

Brunner, D. E. 1939. Das Gebot und die Ordnungen: entwurf einer protestan. tisch - theologischen Etik. Zürich: Zwingli.

Calvin, J. 1956. Institutie of onderwijzing in de christelljke godsdienst, 3 dle., 4de dr. (Uit Latyn vertaal deur A. Sizoo.) Delft: Meinema.

Geiger, M. 1954. Wesen und Aufgabe kirchlicher Ordnung. (In Theologisch studien herausgegeben von Karl Barth, Heft, 42. Zürich: Evangelischer Verlag.)

Heyns, J. A. 1977. Die kerk. Pretoria N.G. Kerk-boekhandel.

Hovius, J. 1962. Het verband tussen onze belijdenis en onze kerkorde. Sneek: Weissenbach.

Jansen, J. 1923. Korte verklaring van de kerkenordening Kampen: Kok.

Kuyper, A. 1898. Van het kerkelijk ambt (In Gereformeerde Stemmen, 2de serie, nr. 1. Rotterdam: Mannenvereniging.)

Nauta, D. 1971. Verklaring van de kerkorde van de Gereformeerde Korken in Nederland. Kampen: Kok.

Roeleveld, L. 1972. Beginselen van kerkelijke rechtspraak. In die Skr:flig, 6 (21) : 41-51, Maart.

Rutgers, F. L. 1890. De geldigheid van de oude kerkordeninge der Nederlandsche Gereformeerde Kerken. Amsterdam: Wormser.

Spoelstra B. 1978. Die gesag van die sinode. Studia Historia Ecclesiasticae III. Kerkhistoriese Werkgemeenskap van Suid-Afrika. 
Van Dellen, I. en Momsma, M. 1941. The Church order commentary: being a brief explanation of the church order of the Christian Reformed Church. Grand Rapids, Mich.: Zondervan.

Van den Berg, M. R. 1969. De gekerkerde kerk. Amsterdam: Buijten en Schip perheijn.

Van der Linde, G. P. L. 1980081. Kerkreg, dl. 1. (Ongepubliseerde klasdiktaat, Teologiese Skool: PU vir CHO).

'977/78. Die kerkorde van die Gereformeerde Kerk in Suid-Afrika. (Ongepubliseerde klasdiktaat, Teologiese Skool: PU vir CHO).

1965. Die Grondbeginsels van die presbiteriale kerkregeringstelsel. Potchefstroom: Pro Rege.

Van der Walt, J. J. 1976. Christus as Hoof van die kerk en die presbiteriale kerkregering. Potchefstroom: Pro Rege.

Van Staden, F. A. H. 1973. Kerkorde in die geskiedenis van die Nederduitse Gereformeerde Kerk(e) in Suid-Afrika 1652-1970. (Proefskrif (DTh)-Universiteit Pretoria.

Van't Spijker, W. 1972. Goddelijk recht en kerkelijke orde bij Martin Bucer. (Apeldoornse studies, nr. 3. Kampen: Kok). 